\title{
Methods of Tobacco Harm Reduction Among Smokers in Malawi: Case Study of Chitipa, Ntcheu And Balaka Districts
}

Vita Mithi ( $\nabla$ vitavmithi@gmail.com )

Armref Data for Action in Public Health Research

Rebecca S. Dewey

University of Nottingham

\section{Research Article}

Keywords: Tobacco harm reduction, Smokeless, Smoker.

Posted Date: June 11th, 2021

DOl: https://doi.org/10.21203/rs.3.rs-612211/v1

License: (c) (1) This work is licensed under a Creative Commons Attribution 4.0 International License.

Read Full License 


\section{Abstract}

The aim of the study was to investigate the methods of tobacco harm reduction products used by smokers in Malawi, in an attempt to reduce tobacco harm. The study employed a cross-sectional survey, with both quantitative and qualitative data collection, in 3 districts, one from each region across Malawi. Participants were recruited using the technique of snowball sampling. 1,258 current and ex-smokers were recruited, age range 15-55 years. The sample size for each district was calculated using the standard formula with a $95 \%$ confidence interval or significance of $p=0.05$. Tobacco harm reduction products, also known as safer nicotine products, are not widely available in Malawi; as such their use is not statistically significant at $5 \%$. However, the following resources were used to reduce tobacco harm: fruits like Malambe (Baobab), Banana, Masau (Jujube), Mtera (local herbs), sweets, chewing gum, fried maize and milk. Solutions: cigarette filters mixed with water, a mixture of pig milk, tobacco and drinking water. In addition, ngirimbo and chingambwe were used in a smokeless way to reduce tobacco harm. Across Malawi, smokers use local tobacco harm reduction products compared to safer nicotine products. This is compounded by the absence of information on safer nicotine products, a lack of service providers, poverty and use of local smokeless tobacco.

\section{Background}

Tobacco smoking is not just one of the world's largest, preventable health concerns, but also one of the highest contributors to global morbidity and mortality, [1][2]. Smoking tobacco causes exposure to a toxic mixture of chemicals, including carcinogens, which damage nearly every organ system in the human body. Smoke from tobacco cigarettes affects smokers, as well as non-smokers in the form of secondhand smoke,[3]. The burden of disease and smoking prevalence are on the rise in most African countries including in Malawi. Tobacco use is increasing dramatically, making a larger proportion of the population vulnerable to tobacco-related diseases,[4]. Most of the African countries are in the early stages of a tobacco epidemic and are yet to experience the full consequences of tobacco-related disease and death, [5]. In Malawi, the prevalence of tobacco smoking increases gradually with age, [6], with young people being the primary target of the tobacco industry since they make up a larger proportion (47.96\%) of the population and are a prime target audience for expanding the tobacco market, [7]. The World Health Organization Framework Convention for Tobacco Control (WHO, FCTC) and use of tobacco harm reduction products have raised both interest and controversy in public health settings, with reports that Safer Nicotine Products (SNP), also known as tobacco harm reduction products, offer a gateway to reduce tobacco smoking,[8]. Tobacco harm reduction products have the potential to improve the health of smokers and the general population,[9]. The Malawi government does little to protect and promote good health and well-being (United Nations Development Programme, Sustainable Development Goal 3) of its consumers, despite the fact that tobacco is the economic backbone of the country,[10]. Tobacco harm reduction products are scarcely found at local markets. This leaves consumers with little option but to use cigarettes and local smokeless tobacco products,[11]. Smokers independently utilize local smokeless tobacco as a tobacco harm reduction product. The government neither offers smoking cessation 
assistance nor promote the sale of safer nicotine products such as nicotine patches and gum,[6].Tobacco harm reduction products can be divided into four main formats; medicines containing nicotine, Snus and snuff, e-cigarettes, and combustion-free cigarettes,[12]. Little is known by the public about ways to reduce or quit smoking using safer nicotine products,[13]. Research shows that the focus is on reducing the initiation of tobacco smoking and harms,[14][15]. There is an absence of literature on the nature, and use, of various tobacco harm reduction products in Malawi, as the burden of smoking prevalence and associated disease continue to rise in Malawi,[16]. Efforts to reduce tobacco harm are rare with limited preventive or therapeutic interventions tailored towards encouraging smoking cessation,[17].

\section{Methodology}

\section{Study Areas and Design}

This study used an exploratory mixed method design, involving the collection of quantitative and qualitative data in order to investigate the methods of tobacco harm reduction products used by smokers in Malawi. The study addressed the following questions: What are the factors affecting the use and access to tobacco harm reduction products and services? What kinds of tobacco harm reduction methods are available and used? What are the perceptions and attitudes on tobacco harm reduction products? As a representative sample of the national population, the sample comprised people in urban areas of Chitipa district in the north, Ntcheu district in the center and Balaka district in the south.

\section{Study Population/target population}

The study population comprised ex-smokers and current smokers, including both males and females, with age range 15-55 years. The study included ex-smokers in order to understand the resources that they had used to quit smoking. The study also included current smokers in order to identify the methods they used to overcome cravings when smoking was not an option. Those that had smoked in the six months prior to the commencement of the survey were classified as current smokers. Those that had not smoked in the previous six months, but had previously smoked, were classified as ex-smokers. Individuals that had never smoked were excluded from the sample. A snowball random sampling technique was used to recruit the participants. The sample size for each district was calculated using the standard simplified formula published by Yamane in $1967\left(\mathbf{n}=\mathbf{N} / 1+\mathbf{N}(\mathbf{e})^{2}\right)$, with a 95\% confidence interval, where $\mathbf{n}$ is the sample size, $\mathbf{N}$ is the size of the population and $\mathbf{e}$ is the margin of error.

\section{Data collection techniques, tools and statistical analysis}

The questionnaire used both open and closed ended questions. The questionnaire was administered by in-person interview by a team of data collectors. Interviews were conducted in the local language of the area (Tumbuka, Lambya and Chichewa). Data were analyzed using SPSS (Statistical Package for the Social Sciences, IBM) and Excel (Microsoft) by generating descriptive statistics for quantitative data analysis and graphical representation of outcomes. A p-value of less than 0.05 was considered as statistically significant. Qualitative data in the form of responses to open-ended questions were 
transcribed into English and entered into a codebook. Thematic analysis of these responses was then performed.

\section{Results}

\section{Study Population}

1,258 smokers were recruited in three districts of Malawi, comprising men and women aged between 15 and 55 years. Participant demographic characteristics are presented in Table 1. In each district the study registered a higher number of male smokers than female smokers. However, Balaka district had a higher number of female smokers than other districts. Most smokers were married and not educated. The highest level of education completed ranges from senior primary to senior secondary. Only a few smokers had attended tertiary education.

\section{Factors Affecting Access and Use of Tobacco Harm Reduction Products Lack of Information}

The smokers expressed that they lack information on Safer Nicotine Products (SNP) and had low levels of understanding of safer alternatives to smoking tobacco. They thought that such products were unavailable and more likely to be addictive and deadly compared to tobacco cigarettes.

..."I do not know of tobacco harm reduction products, but I use chewing gum or sweets, which are available on the market".... a smoker in Balaka district.

... "Source of information is not available to everyone"... a smoker in Ntcheu.

..."Those products may be worse than the products that are advertised e.g. embassy"... a smoker in Chitipa.

\section{Geographical location}

Smokers in Ntcheu district stressed that geographical location plays a vital role in their ability to gain information on issues concerning their health. Smokers perceived that living in a remote geographical area is a barrier to accessing information concerning tobacco harm reduction products and services.

... "Area where am coming from, difficult to receive information"... smokers in Ntcheu.

\section{Lack of Media Influence}

The media does not advertise safer alternatives to smoking tobacco or their potential to reduce harm. This further gives the smokers an impression that SNP are bad. 
..." It means the products are not available in Malawi and it suggests that the products are bad ones"... "They hazardous"... smokers in Chitipa

Smokers emphasized that the media corporations are restricted by the tobacco companies. Since tobacco harm reduction products are safer compared to cigarettes, they have the potential to threaten the tobacco and cigarette industries.

..."They are afraid of killing the business of tobacco"... "harmful to human"... "Maybe the companies that produce cigarettes restricts"... smokers in Ntcheu.

..."I think the government is not providing enough effort"...and... "Lack of seriousness of the companies"... smokers in Balaka.

\section{Poverty and High Levels of Cigarettes}

High levels of poverty and the availability of cheap tobacco cigarettes in regional markets are facilitators for smoking tobacco.

... “Cigarettes are everywhere so I cannot stop smoking”... a smoker in Chitipa district.

... "Poverty, don't have materials that I can get the information"... a smoker in Ntcheu.

... "Remove some companies that make tobacco"... a smoker in Balaka.

\section{Availability of Local Tobacco Harm Reduction Resources and Addiction}

The smokers perceived that they are familiar with (or even habituated to) the locally-available tobacco harm reduction resources and products, and they are unaware that they can still get the effect of nicotine with the use of novel tobacco harm reduction products, when compared to those that are easily available.

... "used to the locals" ... "fear of addiction...and recovery is very expensive in Malawi"... smokers in Chitipa.

\section{Lack of Tobacco Harm Reduction Access points/Clinics}

The smokers articulated that the existence of smoking cessation clinics or tobacco harm reduction services would encourage a number of smokers to seek out these services and attempt to quit smoking. They thought that the government should introduce ways to ensure that tobacco harm reduction products are available and accessible.

..."Introduce a department in the hospital to handle all issues related to tobacco harm reduction"... a smoker in Chitipa.

... "Government should make them available on the market for free"... a smoker in Ntcheu. 
..."Publicizing/GVT should allow this harm reduction be on public"... a smoker in Balaka.

There was prevalent belief that tobacco harm reduction products or safer alternatives such as electronic cigarettes, nicotine replacement therapies (NRT), heat not burn (HNB), snus and pharmacotherapies are not available on the market. This is statistically significant, with $P=0.041$ for Chitipa district, $P=0.038$ for Ntcheu district and $\mathrm{P}=0.040$ for Balaka district, see Table 2 .

\section{Tobacco Harm Reduction Methods, Resources and Products Available}

Tobacco harm reduction methods, resources and products used include; fruits like malambe (baobab), banana, masau (jujube); mtera (local herbs); janus (sweets) and chocolate; fried maize; milk; chewing gum and consuming soaked tobacco in tea or juice.

Some smokers replaced smoking tobacco with using preparations such as solutions made from sugar, cigarette filters mixed with water, and a mixture of pig milk, tobacco and drinking water. These solutions are perceived to have the potential to reduce the appetite for cigarettes. They are perceived to provide tobacco harm reduction since there is no smoke or tar production, although nothing is known about their efficacy or toxicity.

..."I don't know tobacco harm reduction products...but / sell chingambwe myself'... a smoker in Chitipa district.

..." Mostly I use Sweets like Janus, The appetite of smoking was reduced"... a smoker in Ntcheu district.

Smokers also use smokeless tobacco products (STP) such as Chingambwe and Ngirimbo. Chingambwe is raw tobacco that is dried and pounded into small tablets for easy consumption. It is consumed by snuffing, put in the nose and placed between the lower lip and gum. Sometimes it is soaked in water and taken as a drink. Again, it is perceived as a tobacco harm reduction product due to the absence of combustion.

..."Chingambwe mainly when it's smokeless, ngirimbo, Chocolate sweets"... smoker in Chitipa.

The absence of safer nicotine products on the market indicates that smokers rarely use them; which is statistically significant in Chitipa $(P=0.030)$, Ntcheu $(P=0.033)$ and Balaka $(P=0.023)$ in Table 3.

\section{Awareness of Smokers on Tobacco Harm Reduction Products}

Smokers clearly said that they are not aware of the existence of tobacco harm reduction products.

... "Do not have any knowledge, and are not locally available"... a smoker in Balaka.

..."Lack of knowledge and poverty"... a smoker in Chitipa. 
..."I don't know them"... a smoker in Ntcheu.

\section{Perceptions and Attitude of Smokers towards Tobacco Harm Reduction Products}

The widespread use of tobacco harm reduction products depends on consumer preference, experience, availability of the products and the ability to alleviate the health issues associated with smoking cigarettes.

..."I think they may help reduce cases of TB and lung Cancer"... a smoker in Ntcheu District.

..."I think it's because they are developed to reduce the risks that someone can have when smoking"... a smoker in Chitipa.

"I know the smoke in cigarettes is bad for my health"..."Maybe if they adopt tobacco harm reduction products"... a smoker in Balaka.

Smokers articulated that it is not easy to quit smoking but approved the notion of tobacco harm reduction products as safer alternatives; since they may provide smokers a higher chance of being able to quit smoking tobacco.

..."I would love to see these products in shops as they will help us improve our health"... a smoker in Chitipa district.

... "It can help because I once got sick because of smoking it can help me stop"... a smoker in Ntcheu District.

... "It's hard to quit, Maybe if they adopt tobacco harm reduction products"... a smoker in Balaka District.

\section{Discussion}

\section{Study Population}

There were larger numbers of male than female smokers (both former and current smokers). This is in line with the National Statistical Office demographic health survey report, which stated that a high population of people in the country who use or smoke tobacco are men, with less than $1 \%$ of women using tobacco,[11]. The study also suggested that most people who smoke did not receive a high level of formal education,[18].

\section{State of Tobacco Harm Reduction Products}

The study findings are consistent with the WHO, [6] and Global State of Tobacco Harm Reduction,[8] reports, which affirm that, in Malawi, there is little provision of safer alternatives and programs aimed at reducing tobacco consumption are absent. Smokers tend to use temporal measures and traditional 
smokeless tobacco,[18] to moderate their use. The study shows that the use of safer nicotine products is low in Malawi,[19][20]. That being the case, there is a need to ensure that safer nicotine products are made available in order to assist in smoking cessation,[21] and reduce harm.

This research clearly reveals that there is a need for investments aimed at adopting these products as therapeutic measures tailored to the local setting to best assist smokers trying to quit smoking tobacco, [2]. Introducing SNP on the markets as a medicinal product,[22], wholly to be administered to humans for medicinal purposes,[23][24], would significantly increase the awareness of the general public of these products,[25]. SNP would be administered for the prevention or reduction of mental or physiological problems by public and private hospitals, under the treatment of psychoactive drug use (which includes tobacco). In this way, it would assist with smoking cessation in a similar way to the system in England, [9]. However, recognizing SNPs as medical products brings many potential barriers, including the cost of licensing the product, limiting the availability for medical dispensaries, and stifling innovation, which may make retailers lose interest in procuring and selling them.

\section{Access to Information}

Smokers do not have access to basic information about tobacco harm reduction products. The lack of access points like pharmacies, clinics or hospital departments promoting smoking cessation and the provision of safer alternatives, has left smokers with unmet needs. It is desirable that the smokers should have access to correct and current information to enable them to minimize the risks to their health, [26].

Media utilization in sub Saharan Africa is well-known as an important contributing factor to tobacco use, [27]. The same media could be a key to overcoming the geographical barriers, thus enabling smokers to gain accurate and credible information. Information dissemination through local media would encourage motivation to quit (or change their method of use) among existing tobacco users. In addition, the absence of companies producing SNP in Malawi gives freedom to the tobacco industry to promote different flavored cigarettes as the only option to consume nicotine, [28].

\section{High Levels of Cigarettes, Use of Local Harm Reduction Methods and Poverty}

Smokers are controlled, and driven into smoking habits by poverty,[18]. This means that they live below the international poverty line of $\$ 1.90$ USD per day,[29]. As such, purchasing SNP would be a challenge. Although many smokers live below the international poverty line, they are able to purchase cigarettes or raw tobacco as they are cheap and readily available,[24]. A single cigarette or bundle of smokeless tobacco (see Figs. 1, 2, 3 and 4) costs 50 Malawi Kwacha (Malawi currency) which is equivalent to $\$ 0.068$ USD.

Smokers use smokeless substances such as Ngirimbo and Chingambwe. Ngirimbo is a tobacco product that is mostly used in Chitipa district and is found on the black market there. It is tobacco pounded into a fine powder, mixed with water or alcohol or any other solvent for consumption and is dark in colour. It is consumed by being placed between the lower lip and gum, in a similar way to snus. Many young smokers 
in Chitipa district prefer ngirimbo to cigarettes because during consumption, there is no experience of chest pain from inhaling and exhaling smoke. The preference and consumption of traditional smokeless tobacco such as Chingambwe and Ngirimbo indicate that they are likely to be pleasurable. However, the quantity of nicotine present and the health effects of Chingambwe and Ngirimbo are unknown. Furthermore, people use alternatives shown in Fig. 4 below.

Substituting and changing tobacco, with its characteristic carcinogenic content, with nicotine containing products such as Electronic Nicotine Delivery Systems (ENDS), snus and nicotine replacement therapies would reduce the harm caused to tobacco users, [30] These products would replace the use of traditional smokeless tobacco through informed approaches and clinical trials, with evidence showing that they are significantly less harmful compared to local smokeless tobacco or cigarette smoking, [31]. This would be helpful in mitigating the erroneous negative perception of tobacco harm reduction products and may lead to a wider understanding of the potential for substantial reduction of risk and harm, [32].

\section{Knowledge on Tobacco Harm Reduction Products}

Tobacco harm reduction products give the user the opportunity to avoid or significantly decrease the serious health risks associated with tobacco smoking. This is particularly true for those with underlying respiratory illnesses or tuberculosis. Reduced dependence on tobacco or cigarettes can bring economic benefits as well as benefits to both individual and public health,[32]. Nicotine users are aided in the consumption of nicotine without inhaling tobacco smoke containing tar and toxic chemicals, [21]. Smokers who switch to safer nicotine products are less likely to influence young people to take up smoking, [14].

\section{Conclusion And Recommendation}

Across Malawi, there is a general lack of awareness and use of safer nicotine products compared to local tobacco harm reduction products. This is compounded by low levels of education, the lack of availability of tobacco harm reduction resources and the perceived absence of health problems from the use of local smokeless tobacco lead smokers to have a negative perception of safer nicotine products. This is the key preventative factor that precludes smokers from seeking tobacco harm reduction products.

\section{Implications}

- The absence of tobacco harm reduction policies continues to lead smokers towards the use of potentially hazardous (or at least untested) smokeless tobacco products.

- The absence of tobacco harm reduction products gives opportunities for cigarette companies to further expand their markets, with detriment to the public health of Malawi.

\section{Recommendations}

Therefore, it is recommended that: 
- The government of Malawi should formulate policies and regulations tailored towards reducing smoking behaviours and the adoption of tobacco harm reduction products.

- Tobacco harm reduction companies, advocates, district health offices and other responsible agencies should increase anti-tobacco media campaigns using local and mass media (TV, radio) and other communication. Support groups for tobacco harm reduction should be formulated. Furthermore, fundamental measures for educating the community on tobacco harm reduction should be disseminated through existing community health workers since the population is aware of the various services they deliver. Integrating tobacco harm reduction into community health work programs would help to ensure effectiveness, efficiency and sustainability.

- The government should scale up smoking cessation interventions and foster local health departments to develop tobacco smoking prevention strategies to inform the community on the consequences of tobacco smoking and the availability of SNPs. Further, district hospitals should ensure that health professionals are trained in counseling and medicating for tobacco harm reduction.

- Current smokers should develop an association tailored at ensuring that they have access to services aimed at reducing the net damage to health for tobacco users that are unable to stop using tobacco.

\section{Areas of Further Research}

There is need for more research on:

- The prevalence of use, health benefits, effectiveness and efficacy of local tobacco harm reduction products and resources used as tobacco replacements.

- Nicotine levels found in traditional smokeless tobacco and clinical interventional trials and case studies of tobacco health reduction products.

- Tobacco health reduction as a return on investment. The government and health promotion agencies should consider the prospect of these products as an investment. This would help reduce poverty levels among smokers.

- Tobacco harm reduction should be included in the health sciences courses of higher education institutions, to ensure that healthcare professionals have the capacity to advise and deal with the use of this psychoactive drug.

\section{Abbreviations}

E.Cig Electronic Cigarette

ENDS Electronic Nicotine Delivery System

FCTC Framework Convention for Tobacco Control

FSFW Foundation for Smoke Free World 
HNB Heat Not Burn

KAC Knowledge Action Change

MoH Ministry of Health and Population

NHSRC National Health Sciences Research Committee

NRT Nicotine Replacement Therapies

SDGs Sustainable Development Goals

SNP Safer Nicotine Products

SPSS Statistical Package for Social Sciences

STP Smokeless Tobacco Products

THR Tobacco Harm Reduction

THRP Tobacco Harm Reduction Product

USD United States Dollar

WHO World Health Organization

\section{Declarations}

\section{Acknowledgements}

I am thankful to God for his favour and grace of knowledge and wisdom to accomplish this research. I convey my gratitude to Knowledge Action Change (KAC), for funding this research through the Tobacco Harm Reduction Scholarship Programme. Special thanks to my family, Wilfred Jekete and Jon Derricott for their support. Special thanks to Professor Rajesh N. Sharan, PHD., for the guidance and mentorship throughout the research.

\section{Funding}

This study was funded by Knowledge Action Change. The funder did not take any part in designing the study methods, collection, analysis and interpretation of data or in writing the manuscript.

\section{Availability of data and materials}

All raw and analyzed data are available from the author upon request. 


\section{Authors' contributions}

VM composed the proposal, implemented the research, conducted data collection and analysis. RD worked on language, drafts and content of the paper. The final manuscript was read and approved by authors.

\section{Corresponding author}

Correspondence to Vita Mithi.

\section{Competing interests}

The authors have no competing interests.

\section{Consent for publication}

Not applicable.

\section{Ethics approval and consent to participate}

The study was approved by National Health Sciences Research Committee (NHSRC) or Ministry of Health (MoH) (Approval Number: 2403). Prior to data collection, consent letters were obtained from District Health Offices and District Councils. The consent or approval letters articulated the core purpose of the study to inform study participants. Participant data were de-identified for the safety and protection of participants.

\section{References}

1. Network of African Science Academies. "Preventing a tobacco epidemic in Africa: A call for effective action to support health, social and economic development," p. 52, 2014.

2. Magitta, N. F. "Epidemiology of tobacco use and dependence in Sub-Saharan Africa: A systematic review.", J Pulmonol Clin Res., vol. 2, no. 1, pp. 9-15, 2018.

3. WHO report on the global tobacco epidemic 2019. https://www.who.int/tobacco/global_report/en/ accessed on 30th July 2019.

4. Chavula, J. "Tobacco kills 5700 in Malawi-Global Atlas-The Nation Online. htpps://mwnation.com > tobacco-kills-5-700-malawi-global-atlas-2/. retrieved on 22nd April, 2020.," 2018.

5. Drope S.; Schluger; Cahn.; Drope.; Hamill.; Islami.; Liber.; Nargis. The Tobacco Atlas. Atlanta: American Cancer Society and Vital Strategies. 2018.

6. W H O. "WHO report on the global tobacco epidemic, 2017 Country profile," 2017. 
7. National Statistical office. "2018 Malawi population and housing census Main report," Genet. Med., vol. 8, no. 5 SUPPL. 1, pp. 12S-252S, 2018, doi: 10.1097/01.gim.0000223467.60151.02.

8. Shapiro, H. "No Fire, No Smoke: The Global State of Tobacco Harm Reduction 2018," p. 128, 2018.

9. Mcneill, A. “McNeill-Hajek_report_authors_note_on_evidence_for_95_estimate," 2014.

10. Drope, J.; Makoka, D.; Lencucha, R.; Appau, A. "Farm-level economics of tobacco production in Malawi," no. May, p. 54, 2016.

11. National Statistical Office. "Malawi Demographic and Health Survey 2015-16," Natl. Stat. Off. DHS Progr., pp. 1-658, 2017, doi: http://www.measuredhs.com/.

12. Kiviniemi, M. T.; Kozlowski, L. T. "Deficiencies in public understanding about tobacco harm reduction: Results from a United States national survey," Harm Reduct. J., vol. 12, no. 1, pp. 8-10, 2015, doi: 10.1186/s12954-015-0055-0.

13. Stratton, K.; Shetty P.; Wallace, R.; Bondurant, S. "Clearing the smoke: The science base for tobacco harm reduction - Executive summary," Tob. Control, vol. 10, no. 2, pp. 189-195, 2001, doi: 10.1136/tc.10.2.189.

14. Stubbs, B.; Veronese, N.; Vancampfort, D.; Prina, A. M.; Lin, P. Y.; Tseng, P. T.; Evangelou, E.; Solmi, M.; Kohler, C.; Carvalho, A. F.; Koyanagi, A. "Perceived stress and smoking across 41 countries: A global perspective across Europe, Africa, Asia and the Americas," Sci. Rep., vol. 7, no. 1, pp. 1-8, 2017, doi: 10.1038/s41598-017-07579-w.

15. Muula, A. S. "Prevalence and determinants of cigarette smoking among adolescents in Blantyre City, Malawi.," Tanzan. Health Res. Bull., vol. 9, no. 1, pp. 48-51, 2007, doi: 10.4314/thrb.v9i1.14292.

16. Ayo-Yusuf, O. A.; Burns, D. M. "The complexity of 'harm reduction' with smokeless tobacco as an approach to tobacco control in low-income and middle-income countries," Tob. Control, vol. 21, no. 2, pp. 245-251, 2012, doi: 10.1136/tobaccocontrol-2011-050367.

17. Centers for Disease Control and Prevention. "Best Practices User Guide: Health Equity in Tobacco Prevention and Control," pp. 1-52, 2015.

18. Mamudu, H. M.; John, R. M.; Veeranki, S. P.; Ouma, A. E. O. "The odd man out in Sub-Saharan Africa: Understanding the tobacco use prevalence in Madagascar," BMC Public Health, vol. 13, no. 1, pp. 111, 2013, doi: 10.1186/1471-2458-13-856.

19. Annechino, R.; Antin, T. M. J. "Truth telling about tobacco and nicotine," International Journal of Environmental Research and Public Health, vol. 16, no. 4. pp. 12-16, 2019, doi: 10.3390/ijerph16040530.

20. Blecher, E.; Ross, H. "Tobacco Use in Africa: Tobacco Control through Prevention," Am. Cancer Soc., 2013.

21. Omarjee, M. "Electronic Nicotine Delivery Systems: Approach to Regulation in South Africa," no. November, 2015.

22. Rodu, B.; Godshall, W. T. "Tobacco harm reduction: An alternative cessation strategy for inveterate smokers," Harm Reduction Journal, vol. 3. pp. 1-23, 2006, doi: 10.1186/1477-7517-3-37. 
23. Mcneill, A.; Brose, L.; Calder, R.; Hitchman, S.; Hajek, P.; McRobbie, H. “E-cigarettes: an evidence update," Public Heal. Engl., p. 111, 2015.

24. Desalu, O. O.; Iseh, K. R.; Olokoba, A. B.; Salawu, F. K.; Danburam, A. "Smokeless tobacco use in adult nigerian population," Niger. J. Clin. Pract., vol. 13, no. 4, pp. 382-387, 2010.

25. Glover M.; Phillips, C. V. "Preventing risk of disease among adults versus preventing initiation to vaping. Simplistic lifeboat thinking not applicable .," pp. 1-21, 2019.

26. Fagerström K. O.; Bridgman, K. "Tobacco harm reduction: The need for new products that can compete with cigarettes," Addictive Behaviors, vol. 39, no. 3. The Authors, pp. 507-511, 2014, doi: 10.1016/j.addbeh.2013.11.002.

27. Achia, T. N. O. "Tobacco use and mass media utilization in sub-Saharan Africa," PLoS One, vol. 10, no. 2 , pp. $1-16,2015$, doi: $10.1371 /$ journal.pone. 0117219.

28. Phillips, C. V. "Debunking the claim that abstinence is usually healthier for smokers than switching to a low-risk alternative, and other observations about anti-tobacco-harm-reduction arguments," Harm Reduct. J., vol. 6, p. 29, 2009, doi: 10.1186/1477-7517-6-29.

29. Ms. Anna B Gilmore, PhD1; Gary Fooks, PhD1; Jeffrey Drope, PhD2,3, Stella Aguinaga Bialous, DrPH4, and Rachel Rose Jackson, "Middle Income Countries Programme," Middle Income Ctries., vol. 385, no. 9972, pp. 1029-1043, 2015, doi: 10.1016/S0140-6736(15)60312-9.Exposing.

30. Farsalinos, K. E.; Romagna, G.; Tsiapras, D.; Kyrzopoulos, S.; Voudris, V. “Characteristics, perceived side effects and benefits of electronic cigarette use: A worldwide survey of more than 19,000 consumers," Int. J. Environ. Res. Public Health, vol. 11, no. 4, pp. 4356-4373, 2014, doi: 10.3390/ijerph110404356.

31. Hajek, P. "E-cigarettes: a new foundation for evidence-based policy and practice," Public Heal. Engl., no. May 2016, 2015.

32. Royal College of Physicians. "Electronic nicotine delivery systems," Pediatrics, vol. 136, no. 5. pp. 1018-1026, 2015, doi: 10.1542/peds.2015-3222.

\section{Tables}

Due to technical limitations, the tables are only available as a download in the supplemental files section.

\section{Figures}




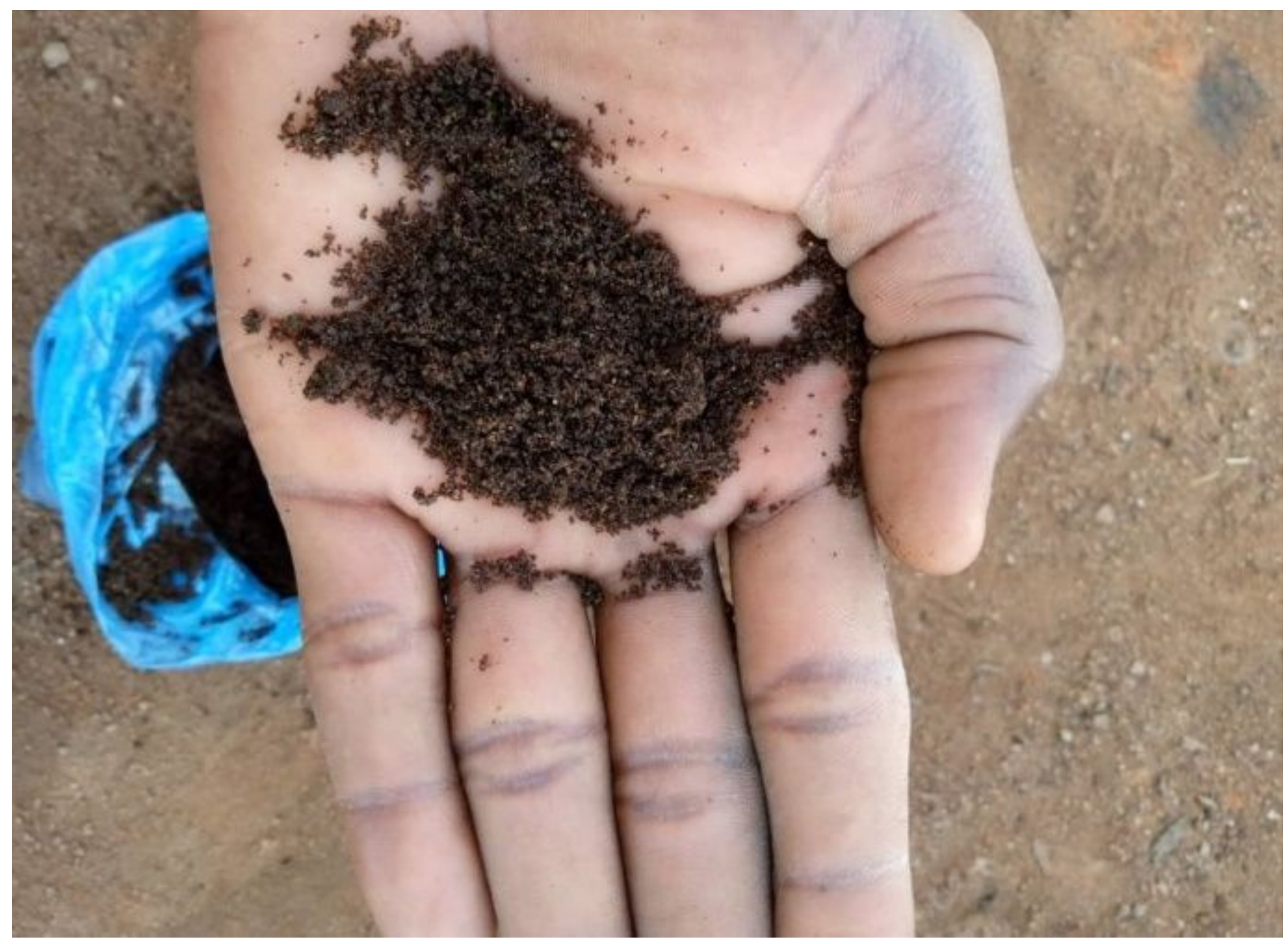

Figure 1

Ngirimbo 


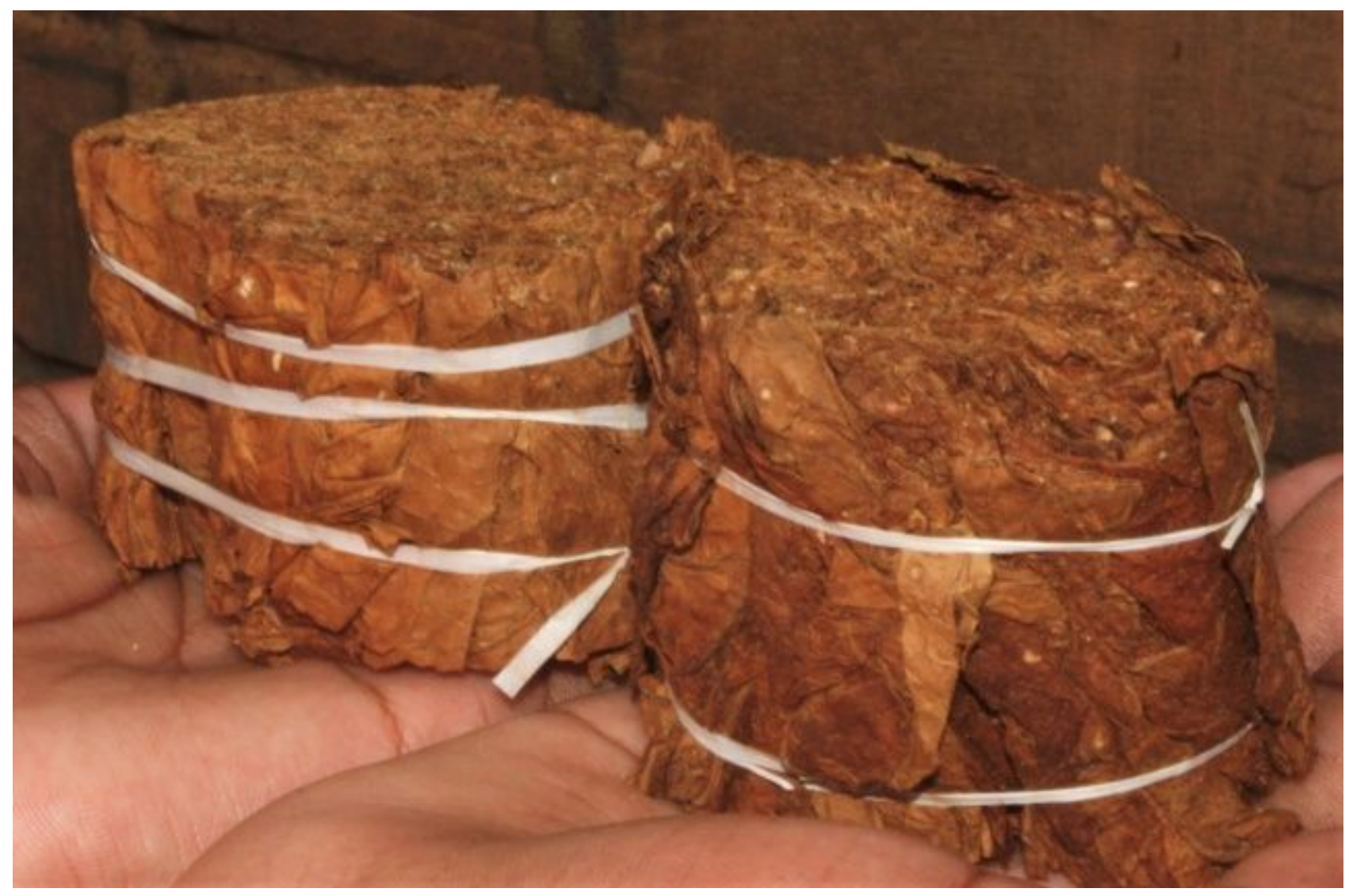

Figure 2

A bundle of Chingambwe worth K50 (50 Malawian Kwachas \$0.068 USD) each.

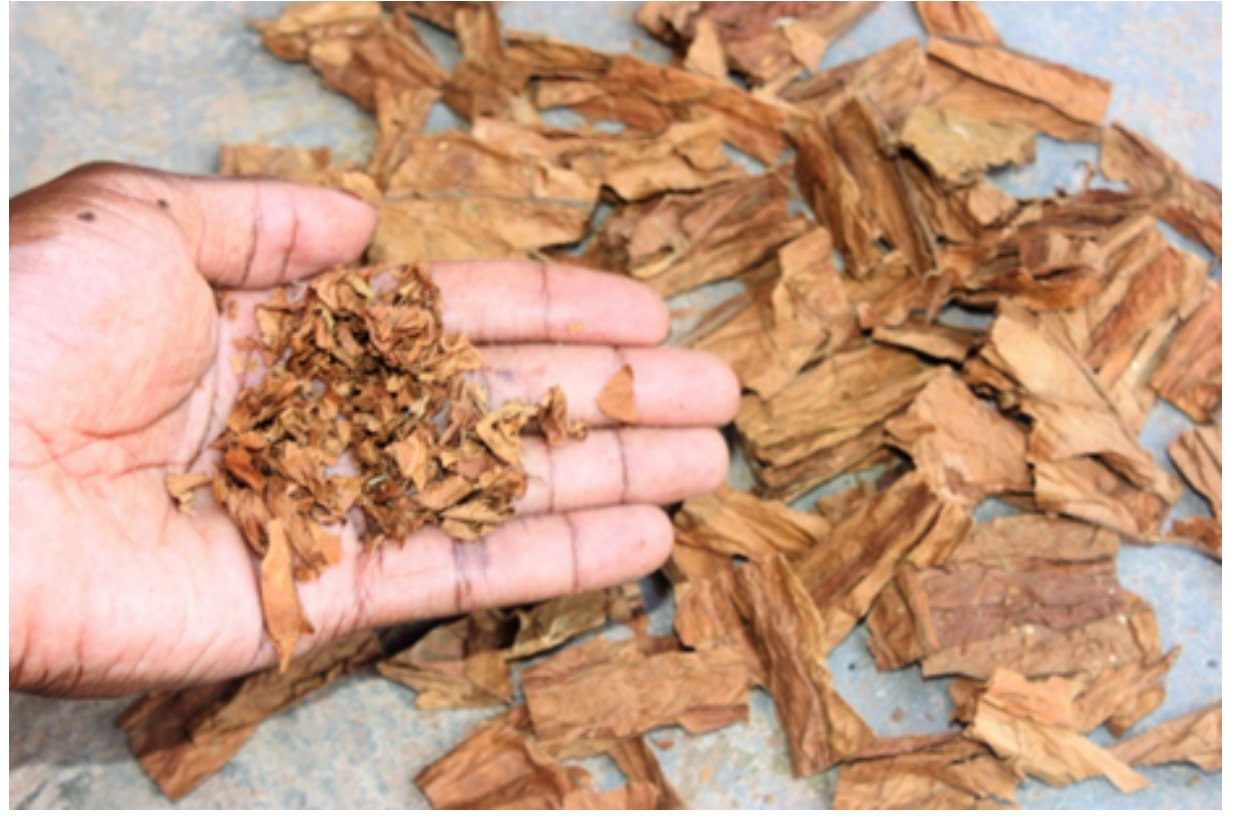

\section{Figure 3}

Chingambwe (local smokeless tobacco) being refined or smoothed for consumption 


\section{Chitipa District}

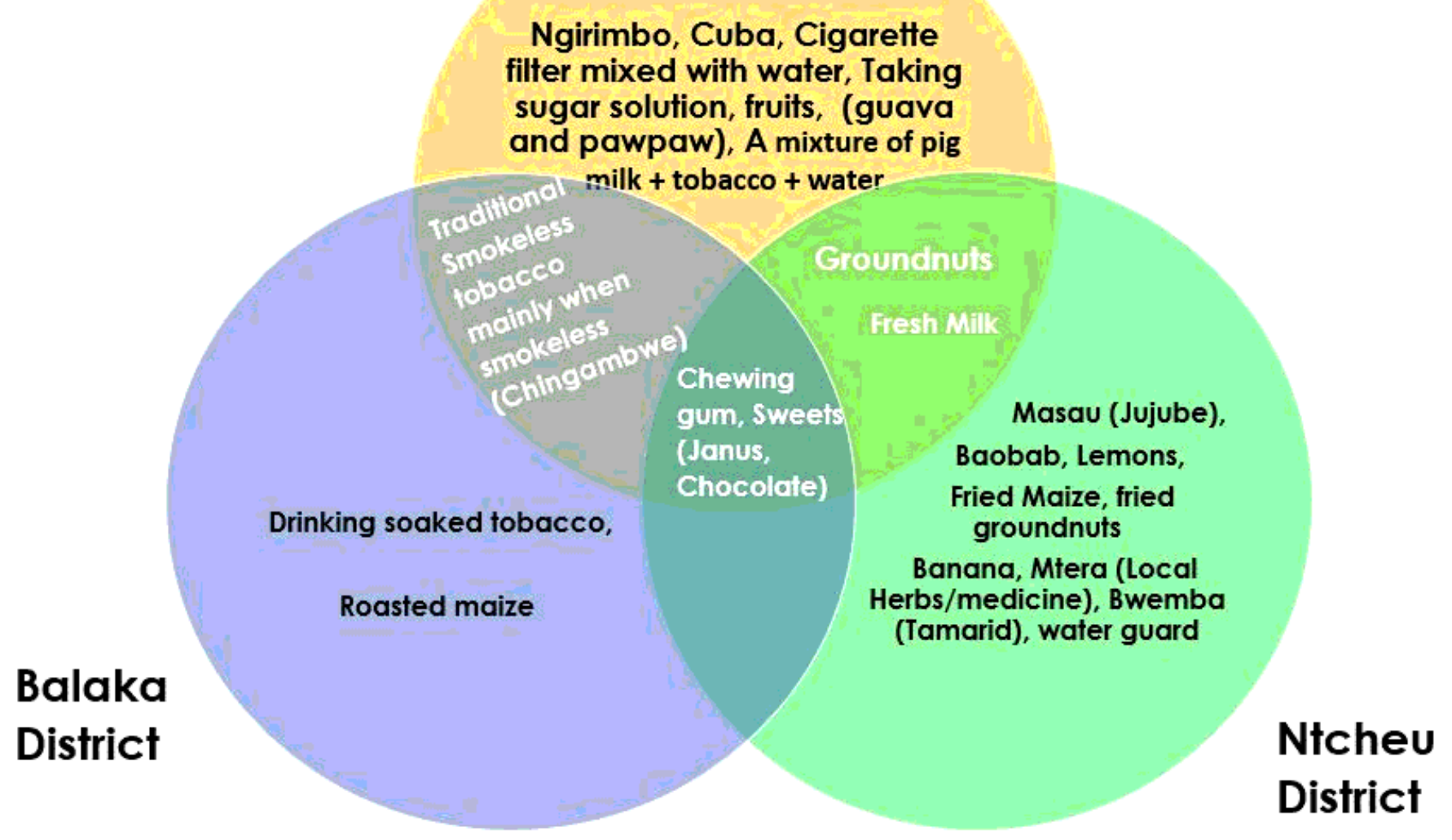

Figure 4

Local Tobacco Harm Reduction Resources and Products

\section{Supplementary Files}

This is a list of supplementary files associated with this preprint. Click to download.

- Tables.pdf 